\title{
Prácticas de resistencia y trabajo social comunitario: forcejeos y tensiones ante las lógicas de dominación del modelo colonial y capitalista*
}

\author{
Practices of resistance and community social work: struggles and tensions \\ in the face of the logics of domination of the colonial and capitalist model
}

Carmen Gloria Jarpa-Arriagada**

\section{Resumen}

Objetivo. Este artículo de reflexión discute la praxis de trabajo comunitario de inserción barrial-territorial y sus tensiones actuales ante la persistencia de lógicas de dominación y la emergencia de prácticas emancipatorias. Metodología. La reflexión crítica y el debate teórico del artículo transita desde conceptos de dominación y resistencia hasta el análisis de lo decolonial y el Trabajo Social-Otro, en un esfuerzo por tejer conexiones entre distintas categorías de análisis para el trabajo social. Resultados. Esta reflexión surge desde una praxis concreta desarrollada al alero del Centro de Intervención e Investigación Social de la Escuela de Trabajo Social (CIISETS) de la Universidad del Bío-Bío, Chile. Las prácticas de resistencia al modelo neoliberal-capitalista encuentran vigencia desde un trabajo social ético-político emancipatorio. Conclusión. En la academia puede existir sinergia entre la recuperación de los saberes populares y la investigación activista como compromiso para la producción de conocimiento situado, histórico y crítico.

Palabras clave: emancipación, dominación, decolonialidad, intervención comunitaria, trabajo social.

\begin{abstract}
Objective: This reflection article discusses the praxis of community work of neighborhood-territorial insertion and its current tensions in the face of the persistence of logics of domination and the emergence of emancipatory practices. Methodology: The critical reflection and theoretical debate of the article go from concepts of domination and resistance, to the analysis of the decolonial and the Social-Other Work in an effort to weave connections between different categories of analysis for Social Work. Results: This reflection arises from a concrete praxis developed under the wing of the Center for Social Intervention and Research of the School of Social Work (CSIRSSW) of Universidad del Bío-Bío, Chile. The practices of resistance to the neoliberal-capitalist model find validity from an emancipatory ethical-political social work. Conclusion: Synergy between the recovery of popular knowledge and activist research as a commitment to the production of situated, historical and critical knowledge can exist in the academy.
\end{abstract}

Key words: emancipation, domination, decoloniality, community intervention, social work.

\footnotetext{
* El artículo recoge la praxis realizada en CIISETS, centro que se dedica a la intervención social bajo con una concepción de trabajo social ético-político emancipatorio

** Universidad del Bío-Bío. Chillán, Chile. E-mail: cjarpa@ubiobio.cl

(D) orcid.org/0000-0002-9896-5649 Google Scholar
} 
Prácticas de resistencia y trabajo social comunitario: forcejeos y tensiones ante las lógicas de dominación del modelo colonial y capitalista

\section{Introducción}

Este artículo invita a un debate sobre la coherencia teórico-práctica y las adhesiones a determinadas matrices epistémicas del trabajo social, específicamente en lo que a intervención comunitaria se refiere. Esta reflexión surge desde una praxis concreta desarrollada al alero del Centro de Intervención e Investigación Social de la Escuela de Trabajo Social (CIISETS), de la Universidad del Bío-Bío, Chillán, Chile.

La Universidad del Bío-Bío es una institución de educación superior, pública y estatal, ubicada en el sur de Chile. Esta institución proporciona formación profesional en las cinco áreas del conocimiento, y debido a que desarrolla docencia, extensión e investigación científica, se considera universidad compleja. La carrera de trabajo social en la UBB tiene 25 años de trayectoria y CIISETS tiene siete años de implementación. Uno de los propósitos centrales de la creación de CIISETS fue responder, por una parte, al principio de responsabilidad social universitaria y su consecuente vinculación bidireccional con el medio, y por otra parte, buscar una forma de resistencia a las prácticas institucionalizadas de los estudiantes para poder proporcionar una experiencia de fuerte compromiso barrial-poblacional. De esta manera, hemos dado una respuesta a una interpelación ético-política al mantener una relación estable con territorios aledaños a la universidad, que se caracterizan por ser poblaciones con alta marginalidad y exclusión.

La tesis de este artículo postula la re-significación del paradigma crítico y su vigencia en nuestra profesión como imprescindible para el trabajo social chileno. Específicamente, planteamos la recuperación del trabajo social ético-político emancipatorio (Guerra, 2007, 2018; Montaño, 2004, 2007), desde un enfoque comunitario de inmersión barrial-territorial.

Afirmo que los trabajadores sociales debemos mantener una vigilancia epistemológica reflexiva-crítica de nuestros saberes, creencias, prejuicios y lógicas de poder. En efecto, nuestra "intervención" (desde su origen lingüístico inclusive), nos debe llevar a preguntarnos constantemente si lo que hacemos lo hacemos desde la predominancia del bien-estar o buen vivir del "otro/a" o desde alguna lógica de dominación o reproducción de desigualdad, como resabio del positivismo incubado en nuestra profesión y de la ideología neoliberal con su fuerte cargamento de embriagadores conceptos como libertad, igualdad de oportunidades, meritocracia e individualismo.

En este contexto, la discusión respecto del desafío de construir un “trabajo social-otro” precisa clarificar el concepto de lo decolonial, la resistencia, la investigación activista, la educación popular, la exclusión, la emancipación, entre otros elementos que hemos ido construyendo como matriz epistemológica, axiológica y praxiológica de nuestro quehacer en CIISETS. 
La estructura del artículo considera un análisis de las tensiones de la intervención comunitaria; un debate sobre las prácticas de resistencia en un país fuertemente capitalista; una precisión de lo que comprendemos por decolonial y trabajo social-otro; una reflexión sobre la viabilidad del trabajo social ético-político emancipatorio en intervención comunitaria; concluyo con algunas consideraciones finales que incluyen propuestas de cómo hacer intervención comunitaria desde un trabajo social-otro.

\section{Discusión}

\section{La intervención comunitaria en trabajo social: tensiones entre emancipación y dominación}

La tensión entre dominación y emancipación constituye una discusión sin clausura en el trabajo social. El examen de distintas perspectivas reconoce la existencia de un trabajo social conservador, un trabajo social crítico y un trabajo social neoconservador (Vivero-Arriagada, 2017b, 2020a). Resulta interesante que, en el despliegue de estas ideas, se realice el reconocimiento explícito de un trabajo social concebido como el aceite que mantiene engrasadas las ruedas del sistema, aludiendo a nuestro papel como productores, mantenedores y reproductores de desigualdades sociales (Guerra, 2007, 2018). En una postura más crítica del trabajo social (a la que adhiero), resulta explícito un rechazo/oposición a las relaciones de poder que impregnan los encuentros de los trabajadores sociales con los usuarios, clientes, sujetos de intervención, actores sociales (conceptos que desde el lenguaje, ya construyen diferencias). Esta postura de rechazo a la asimetría en la intervención social se alimenta de ideas marxianas, gramscianas y freirianas, aludiendo a la tensión dominación/emancipación en nuestra praxis (Drago, Moulian y Vidal, 2011; Jarpa-Arriagada, 2015; Vidal-Molina \& Vargas-Muñoz, 2019; Vivero-Arriagada, 2017b, 2020b), incluyendo además como cuestión estructural al capitalismo y su versión tecnologizada del trabajo social como herencia positivista y eurocéntrica.

En Chile varios/as trabajadores sociales y profesionales de las ciencias sociales se han ocupado de las tensiones del propio trabajo social y del concepto de intervención como herencia eurocentrada. Suárez $(2018,2019)$ afirma que la política social neoliberal instala la intervención como asimétrica y postula la desinstalación de dicha categoría lingüística por otra como la praxis; Vivero-Arriagada (2017a, 2017b, 2020a) afirma la vigencia de un trabajo social neoconservador que aviva la presencia de lo tecnocrático y se mantiene asépticamente distante de las luchas sociales; Canales (2016) plantea la necesidad de que el trabajo social, en código gramsciano, re-descubra el diálogo y la conversación como registros para facilitar procesos autogestionados de reflexión comunitaria; Molina (2012, 2016), analiza el trabajo social posdictadura y apela a la recuperación de la praxis como relación de transformación emancipadora; Vidal-Molina (2016, 2017, 2019) se aproxima al concepto de justicia y a la relación entre ideología, modelo de desarrollo y política social, especialmente de tono 
Prácticas de resistencia y trabajo social comunitario: forcejeos y tensiones ante las lógicas de dominación del modelo colonial y capitalista

neoliberal; en suma, existe una discusión abierta respecto de la tensión entre acciones profesionales encaminadas a la emancipación y la preservación de lógicas dominantes.

Reconocida la tensión, como plantea Fals-Borda (2015), el reto es epistemológico. Ergo, abandonar la dominación supone un esfuerzo genuino y consciente para entender a fondo las implicaciones teórico-prácticas y filosóficas de lo que se hace (Fals-Borda, 2015) y, seguidamente, abandonar aquellas prácticas que están aún en el territorio de la infantilización del otro/a, de la dependencia, de la práctica erudita y de todas aquellas formas de dominación que, vestidas de altruismo, no hacen más que reproducir actuaciones profesionales asistenciales, clientelares y autoritarias.

Si de intervención comunitaria se trata, entonces, la praxis debe entenderse como una acción política para cambiar estructuralmente la sociedad (Fals-Borda, 2015; Gramsci, 1999; Mejías y Suárez, 2017; Suárez, 2019; Vivero-Arriagada, 2017b), a partir de la recomposición del tejido social, de las redes vecinales y barriales, del sentido de la existencia en comunidad, de la lucha por los derechos sociales y de todas aquellas acciones que nos mantengan fuertemente comprometidos con la transformación social. Parte fundamental de esta práctica sub-versiva es la comprensión profunda de los procesos históricos como constituyentes del ser social y como componente de la existencia humana en las comunidades, territorios y lugares, cada uno con sus rasgos subyacentes y peculiares.

\section{Prácticas de resistencia: (de) construcción del saber y hacer sentipensante en un trabajo social gobernado por el mercado}

Las prácticas de resistencia pueden conceptualizarse desde distintos lugares, pero comparten, medularmente, un enérgico cuestionamiento hacia los principios enarbolados por el capitalismo y el modelo de desarrollo neoliberal. De esta manera, una práctica de resistencia puede incluir y anidar cuestiones relativas a la epistemología de la implicación, al aprendizaje relacional, la visibilización de la desigualdad, la asunción de una mirada crítica sobre el cambio social y el poder (Sánchez, 2013), así como una clara oposición a las relaciones de dominación (Zamanillo y Martín, 2011), tanto como la búsqueda incesante de desmantelar la estructura simbólica y social de las asimetrías que mantienen lo subalternizado en el margen (Méndez y Rojas, 2015). Con todo, la riqueza de las prácticas de resistencia proviene de su amplia gama de manifestaciones, desde la más micro y pequeña expresión de desafío a las prácticas anquilosadas y conservadoras, hasta los gigantescos empeños de trabajadores sociales que ejercen la profesión desde una postura militante y crítica.

Resistir es un acto político (Jarpa-Arriagada, 2015) y, fundamentalmente, es un acto éticopolítico. Para lograr que se convierta en un trazo firme es preciso (de)construir nuestro saber y hacer en la disciplina. En efecto, la formación profesional fuertemente mercadizada y los 
enérgicos embates de un modelo de desarrollo que ha puesto en juego una serie de maniobras muy estables y sofisticadas para asegurar su mantenimiento y consolidación, han instalado o reinstalado rasgos fuertemente conservadores en la profesión (Vivero-Arriagada, 2017b, 2020a), con una defensa acérrima de las "competencias" como cimiento de la formación, cuestión que es un guiño incuestionable al mercado. Lamentablemente, el modelo de competencias ya está instalado en las instituciones de educación superior, y hoy solo queda hacer resistencia para tensionar la recuperación de la ética, de la consciencia, de la reflexividad y de lo político, como fundamentos de una actuación profesional comprometida con lo subalterno.

Para "ser" un trabajador social sentipensante y actuar coherentemente, debe existir una dosis fundamental de indignación ante a la desigualdad; de creatividad para buscar incesantemente maneras nuevas y mejores de actuación profesional; de pasión inclaudicable para luchar por cambios sustanciales en las formas actuales de existencia; en fin, un trabajo social que piensa, pero que siente, esto es, un trabajo social sentipensante. En este sentido y tal como plantea Walsh (2013a), no existe un estado nulo de la colonialidad, ergo, no es posible pensar en la negación absoluta de lo colonial, sino más bien en un despliegue incesante de posturas, posicionamientos, horizontes y proyectos de resistir, transgredir, intervenir, in-surgir, crear e incidir (Walsh, 2013a). Con todo, la resistencia debería entenderse como una consciencia viva, fuerte, enérgica, en clara oposición a lo meramente discursivo. Decir que resistimos sin resistir es una declaración muerta y marchita.

Las prácticas de resistencia ocurren en un Chile gobernado por el mercado. Los trabajos de Gaudichaud (2015a, 2015b) iluminan en este tema. Franck Gaudichaud nos describe como un país que hace una "vía al neoliberalismo" en un contexto histórico fuertemente propicio. El golpe de Estado encabezado por Pinochet y la consecuente instalación de una cruda tiranía cívico-militar ofrecieron condiciones suficientes para una persecución violenta del movimiento popular, de la clase obrera y de los sindicatos. La impunidad permitió no sólo detener y tor turar a los adherentes de la Unidad Popular, sino que además permitió detenciones forzosas, exiliados, ejecutados políticos y detenidos desaparecidos. El miedo dio paso a la individualidad y luego, el desarrollo de una economía expansiva, a un brutal consumismo que se sostiene sobre un altísimo endeudamiento. Las relaciones de Pinochet con los ideólogos de la Universidad de Chicago logran instalar profundas reformas económicas y laborales que han consolidado uno de los modelos capitalistas más despiadados del mundo.

En este contexto, Gaudichaud (2015a, 2015b) postula algunas "fisuras" que son expresión de movimientos sociales, pero principalmente del movimiento estudiantil de los años 2006 y 2011, que abre paso a una "crisis de legitimidad" del modelo capitalista-neoliberal. No obstante, Gaudichaud postula que estas fisuras no indican un desmantelamiento del modelo, sobre todo porque la relación capital-trabajo sigue intacta. La preservación del modelo instalado durante la dictadura de Pinochet se explica por la continuidad de las bases económicas y laborales 
Prácticas de resistencia y trabajo social comunitario: forcejeos y tensiones ante las lógicas de dominación del modelo colonial y capitalista

que hicieron los gobiernos de la Concertación de Partidos por la Democracia y luego por el retorno de gobiernos de derecha y la creación de una nueva coalición denominada "Nueva Mayoría".

En este escenario, el capitalismo se mantiene sobre la base de un nuevo tipo de ciudadano, consumidor y desafectado de la política. Trabajo social, como oferta de pregrado, mercadizada y ampliamente diversificada en educación superior, tanto como profesión y disciplina, no escapa a ello. Es justamente allí, en ese intersticio, donde capitalismo, precariedad laboral, visión aséptica y despolitizada confluyen, que asistimos a un trabajo social conservador y neoconservador (Vivero-Arriagada, 2020a), pero también a un país con una enorme desigualdad, segmentación educativa, segregación habitacional, precariedad laboral y nuevas vulneraciones de los derechos humanos (Molina, 2012, 2016); así también emergen las tensiones propias entre las visiones conservadoras, neoconservadoras y críticas. En representación de estas últimas, Suárez (2019) afirma: “Escribo... bajo la 'sospecha' de promover un pensamiento reflexivo-político, estéticamente denso y radicalmente crítico..., ausente de levedad, sin atisbos de inocuidad y en algunos casos con claridad anti-sistémica o detractor de la modernidad colonizadora" (p. 17), lo que representa un nuevo aire, una utopía tal vez, pero que alimenta decididamente las prácticas de resistencia.

\section{Lo de-colonial como fundamento de un trabajo social-otro, icómo nos deshacemos del trabajo social positivista, eurocéntrico y capitalista?}

El trabajo social chileno es un producto cultural y sociohistórico diverso, complejo y paradojal, coherente en sí mismo con nuestra esquizofrenógena sociedad y sus forcejeos entre desigualdad, libertad, arribismo, individualismo y adhesión a uno de los capitalismos más feroces del mundo. Aloja en su trayectoria histórica hitos tan relevantes como haber sido el primer país de América Latina que funda una escuela de formación profesional (la Escuela Alejandro del Río en 1925); haber sido fuente de significativas experiencias para que Paulo Freire, luego de huir de la dictadura brasileña en 1964, consolidará su obra en nuestro país; haber mostrado una clara y enérgica defensa de los derechos humanos en la larga y sangrienta dictadura que nos azotó entre 1973 y 1989, entre algunos ejemplos. Sin embargo, nuestro país también muestra una adhesión importante al modelo de desarrollo neoliberal instalado en la dictadura y consolidado en los gobiernos democráticos desde los 90; mantiene una formación profesional aún gobernada por el positivismo y el modelo funcionalista estructural; aún existen prácticas con altas dosis de asistencialismo, clientelismo, beneficencia y altruismo apolítico; en fin, y como plantea Muñoz (2018), el trabajo social chileno muestra diversidad teórica y contradicciones endémicas que, a mi juicio, es fruto de su devenir histórico.

Diversos autores plantean que hacer el giro decolonial constituye una urgencia histórica. En efecto, los aportes de Catherine Walsh, Aníbal Quijano, Walter Mignolo y Nelson Maldonado- 
Torres, coinciden en presentar el pensamiento decolonial como una llave maestra para transitar hacia una transformación no solo epistémica, sino que también cultural, política y humana (Maldonado-Torres, 2008; Quijano, 2007; Walsh, 2007). Desde esta noción, la construcción de un "trabajo social-otro" constituye un ejercicio permanente de reflexión crítica, de agudeza política, de ética-acción ${ }^{1}$, de compromiso inquebrantable con lo subalterno, lo invisible, lo negado y lo no nombrado. En esta lógica, el chileno Pablo Suárez afirma que los trabajos sociales-otros no implican ruptura, sino que es expresión de una rebeldía presente en los pensamientos críticos de América Latina (Suárez, 2018), y que por tanto pertenece a una matriz cognitiva viva en cada trabajador/a social que logra sacudirse de la osificación que produce la ferocidad del modelo de desarrollo capitalista-neoliberal.

La emergencia de expandir el pensamiento decolonial constituye un desafío y hacerlo en la formación profesional es una exigencia. Para Walsh (2005), nos permite cuestionar "el diseño colonial e imperial de la geopolítica dominante del conocimiento y la subalternización epistemológica, ontológica y humana que esta geopolítica ha venido promoviendo” (p. 17); ergo, lo decolonial supone desmantelar una de las estrategias substanciales de la modernidad, esto es, el planteamiento de un conocimiento científico único y válido, destinado a generar verdades absolutas, casi omniscientes y omnipresentes, en el contexto de un uni-verso incuestionable, al borde del dogma. Desestabilizar el modelo colonial/moderno, capitalista y eurocentrado (Walsh, 2005, 2013b), implica plantear "otro" modelo o modelos posibles; entonces, esta "otra” producción de conocimientos rescata saberes, haceres, poderes, experiencias, vivencias, devenires subalternizados. Lo "otro" es una invitación, pero a la vez una interpelación para que la producción epistémica “otra” promueva la emancipación, integre lo excluido, se haga cargo de la subjetividad "otra” y proponga conscientemente un propósito distinto.

Desde una agudeza y perspicacia desbordante, Walsh (2005) afirma "lo que ofrece un pensamiento-otro es abrir posibilidades críticas, analíticas y utopísticas de trabajar hacia la descolonización de uno mismo, pero más específicamente hacia la decolonialidad de la existencia, del conocimiento y del poder” (p. 21). Por consiguiente, el trabajo social-otro debe respirarse y vivirse desde dentro, como una necesidad, como una pretensión constante, un ideal, sueño o utopía. Ciertamente, muchas urgencias se han ido apagando y asfixiando al alero de un modelo de desarrollo individualista, egoísta y consumista y se ha extendido a la formación profesional con el retorno de una mirada aséptica, despolitizada, objetiva, neutral y descomprometida de un trabajo social funcionalista, clientelista, asistencialista, precario y mercadizado.

Al parecer no existe una fórmula para conseguir un giro decolonial, pero existen proposiciones frescas y trascendentales: Maldonado-Torres (2008) habla de "actitud de-colonial” para

\footnotetext{
${ }^{1}$ He querido, de manera atrevida, plantear el término ética-acción para interpelar aquella ética de bolsillo que se queda en las palabras, pero que no muestra coherencia en el desempeño profesional.
} 
Prácticas de resistencia y trabajo social comunitario: forcejeos y tensiones ante las lógicas de dominación del modelo colonial y capitalista

visibilizar lo que la gente hace, sus prácticas sociales, epistémicas y políticas; Walsh (2005) propone confrontar "lo propio", la deshumanización, el racismo, la racialización, así como la negación y destrucción de los campos-otros del saber; Fals-Borda (2015) nos interpela a rechazar las técnicas que cosifican la relación social y advertir el riesgo de que se conviertan en armas ideológicas a favor de la clase dominante; García-García (2018) pone el acento en hacernos cargo de la violencia epistémica aún presente en nuestras acciones profesionales (juicios, terminología, sello culturalista colonial). En suma, el giro decolonial supone que la principal transformación debe ocurrir en el sujeto, en nosotros mismos, en nuestro devenir cotidiano, en suma, en nuestra existencia. Nada cambiará si nos quedamos en el discurso políticamente correcto, pero radicalmente vacío.

Coincido plenamente con Walsh (2007), en el sentido de que un trabajo social-otro debe asumir la relacionalidad como principio fundante, para explicitar la urgencia de integración, articulación e interconexión entre los elementos de la existencia. Alrededor de este principio clave se tejen redes de conexión, compromiso, sensibilidad y ética-acción para ocuparse del intercambio permanente de saberes y la construcción colectiva del conocimiento. Walsh (2007) resume tres ideas fundamentales para conseguir este principio clave: (i) tensionar los significados mantenidos y reproducidos por las universidades y las ciencias sociales sobre qué es el conocimiento científico; (ii) abrir espacio a los pensamientos/conocimientos otros, entendido como un pensamiento/conocimiento plural desde la(s) diferencia(s) colonial(es); (iii) pensar nuevos lugares de pensamiento dentro y fuera de la universidad, lugares que permitan el debate, diálogo y discusión lógica, así como racionalidades diversas.

Desde los planteamientos de Walsh se desprende la necesidad de crear, configurar, proponer lugares epistémicos de pensamiento-otro donde, de manera situada, los seres humanos podamos experimentar una reconstrucción de nuestras lógicas de poder y de saber, en el marco de nuestra existencia cotidiana y para acelerar el tejido de sociedades más inclusivas, diversas, respetuosas, auténticas y de buen vivir.

\section{El trabajo social ético-político emancipatorio: lo luminoso y lo nebuloso en la intervención comunitaria}

Si partimos de las ideas de Gramsci $(1970,1981,1999)$, quien afirma que el conflicto es un recurso y la autonomía una conquista progresiva y no un estado de cosas, podríamos inferir que la emancipación debe fraguarse en el campo de la consciencia de clase y la disposición a actuar como "clase" (Jarpa-Arriagada, 2015). En este sentido, la dialéctica en Gramsci recupera a un sujeto (individual o colectivo), que se niega constantemente y en esa negación se despliega su ser otro. Esto supone un sujeto inmerso en una red de relaciones que lo modifican y lo reconstituyen en su proceso de desarrollo. Dialécticamente, por tanto, un proceso social es, y al mismo tiempo no es, porque continuamente se niega y se supera. Para Gramsci, en eso 
consiste el devenir. En este devenir, la contradicción es permanente. Desde esta perspectiva, podemos plantear que la hegemonía "se hace" en un proceso contradictorio que involucra a los sujetos dominados desde el conformismo y a los sujetos dominantes desde la persuasión. A no dudarlo, desde el pensamiento gramsciano la hegemonía adquiere ribetes de complejidad, ya que supone una renegociación permanente del "sentido común" como lugar primario de la lucha ideológica.

En efecto, este proceso lo entendemos no como algo exterior y que sucede fuera de los sujetos, sino como un proceso donde los sujetos son protagonistas, incluyendo ideas diversas y hasta antagónicas. En este sentido, el concepto gramsciano de hegemonía aplicado a la educación (en trabajo social o en cualquier disciplina) define una forma de dominación que ejerce el control social a partir del uso de instrumentos ideológicos, con el propósito de imponer una determinada y única visión del mundo sobre los dominados. Lo peculiar de la hegemonía, en el sentido gramsciano, es justamente que esta dominación no se ejerce por imposición o inculcación ideológica, sino que ella radica en la naturalización del control social, que mediante un proceso de saturación, se vuelve cotidiano y por tanto habitual y no cuestionable (Jarpa-Arriagada, 2015).

En atención a lo expresado, afirmo que la relación entre hegemonía y educación se traduce en la utilización de un dispositivo de transmisión ideológica que eleva el capital cultural de los individuos para la adquisición de la conciencia de clase. Este proceso, para Gramsci, lo realizan "los intelectuales” y particularmente los intelectuales que él llama “orgánicos”. De aquí la importancia de la educación, ya que ella desempeña un rol esencial en la formación de los intelectuales del bloque emergente, como también lo desempeña en la gestación del bloque dominante. Por consiguiente, el proceso educativo es trascendente en la construcción de un nuevo sujeto, de un nuevo ciudadano con conciencia de clase (Jarpa-Arriagada, 2015).

En la experiencia de CIISETS, hemos fraguado un proceso de intervención comunitaria que, desde las ideas gramscianas, recupera la necesidad de actuar como intelectuales orgánicos. Bajo esta mirada, hemos dado importancia a la inserción paulatina en los barrios, con respeto irrestricto a sus tiempos y velocidades, reconociendo sus saberes populares y situándolos en una relación comprometida y responsable. Nos miramos continuamente para escudriñar cualquier trazo de asistencialismo o paternalismo. Actuamos, entendiendo al otro/a como un sujeto histórico/a, situado/a en un espacio y momento específico, particular, pero trayendo consigo su memoria, su identidad, sus experiencias. Hacemos grandes esfuerzos para manejar los ciclos de adherencia y desconexión hacia los procesos desarrollados; intentamos comprender que una praxis ética-política emancipatoria no puede caer en el juego de los egos, de las evidencias, de las lógicas del management. Podríamos decir que ese es un lado luminoso.

Un aspecto luminoso, pero a la vez nebuloso, por las constantes contradicciones que genera en la profesión, es la discusión de lo ético-político. Si seguimos a Gramsci, lo político es la 
Prácticas de resistencia y trabajo social comunitario: forcejeos y tensiones ante las lógicas de dominación del modelo colonial y capitalista

ética de lo colectivo, y desde ese “estar” en la profesión, deberíamos lograr coherencia con la revitalización del tejido social perdido, deberíamos renunciar a la neutralidad y a la objetividad y apostar por una mayor "politización”, deberíamos ejercitar más la comprensión de las estructuras sociales que provocan desigualdad y "estar menos" en la queja. En este sentido, coincido con Zamanillo y Martín (2011), cuando afirman "el quehacer político está relacionado con la ética porque la política es ética y viceversa. Se trata pues de la ética-política” (p. 103). En esta misma línea, Zamanillo y Martín (2011) apuestan por un trabajo comunitario que pueda contribuir a contrarrestar los efectos negativos del individualismo, de la atomización, de la fragmentación social, impulsando la co-construcción de un nuevo sujeto individual y colectivo. Adherimos a esta propuesta y la experiencia nos indica que es un proceso que se teje y que discurre lentamente, con vaivenes, avances y retrocesos, y que además nos pone de frente al dilema profundo de estar surcando rumbos que requieren de una deconstrucción de la identidad profesional ligada al saber erudito, para transitar los senderos de la emancipación, recuperando la educación popular.

Uno de los aspectos sombríos lo constituye el dispositivo conceptual inclusión/exclusión o “inclusión excluyente" (Ezcurra, 2011). Esto es, el fenómeno de la exclusión se configura en un difuso recorrido entre la implementación de políticas de inclusión y la exclusión como una manifestación multifactorial de la reproducción social asociada a diferencias socioeconómicas o de capital cultural (Giraldo-Zuluaga, 2015). En este sentido, debemos estar alertas cuando estamos "excluyendo" en una acción de "inclusión", ya que como inclusión y exclusión no constituyen polos opuestos sino una trayectoria, reconocemos que hay acciones que podrían entramparnos en una paradoja que deviene históricamente de la discusión sobre nuestro “objeto de intervención". Cuando intervenimos sobre una comunidad catalogada como problemática, ¿lo hacemos para disminuir la desviación de lo estipulado como "normal” o para sumergirnos en esos procesos respetando sus patrones culturales? ¿Cuánto de exclusión hay en las categorías mujer, pobre, jefe de hogar, niño, vulnerable, carencia, problema? ¿Creemos que lo popular es marginal? Hago una invitación a reflexionar sobre los nudos paradójicos entre conceptos como inclusión/exclusión; colonial/decolonial; libertad/coacción; voluntariedad/ obligatoriedad; participación/manipulación; emancipación/control; derechos universales/ derechos focalizados; entre muchos ejemplos.

Es urgente que reflexionemos profundamente respecto de la inclusión y su ejercicio genuino. Siguiendo a Mezzadra y Neilson (2017), existe "una necesidad urgente de cuestionar la noción generalizada de que la inclusión siempre es un bien que carece de ambigüedades y que promueve una disminución de las desigualdades sociales y económicas” (p. 188). Por cierto, son muchos los que hoy ponen en duda no solo la inclusión per se, sino también las prácticas de acción afirmativa, ya que la frontera entre inclusión y exclusión se ha vuelto difusa y las acciones de exclusión mucho más sofisticadas (Arriagada, 2006; Mezzadra, 2013; Mezzadra y Neilson, 2017; Zepke, 2015, 2018). Por consiguiente, hay que estar alerta a las nuevas y 
elegantes formas de colonialidad que se expresan en los dispositivos de frontera. No cabe duda que la frontera tiene una función excluyente (García-García, 2018), que para el caso de nuestra experiencia en Villa Las Almendras ${ }^{2}$ se manifiesta en exclusión, discriminación, violencia policiaca desmedida, estigmatización de los medios de comunicación, ejecución de acciones que responden a clientelismo o paternalismo, en fin, una amalgama de maniobras que naturalizan una dominación enmascarada.

Desde una consciencia política debemos ocuparnos de advertir tempranamente si la relación profesional que construimos con las comunidades sigue enfatizando el asistencialismo y paternalismo, favoreciendo relaciones asimétricas desde la ayuda y la caridad, desde la dominación y el poder. Por cierto, la dominación y la dependencia ocurren en procesos de coerción y consenso como lo afirma Gramsci, que implica no solo fuerzas exteriores sino también fuerzas interiores que mantienen jerarquías anquilosadas, reproduciendo la heterogeneidad colonial jerárquica (Maldonado-Torres, 2008). Afirmo, por tanto, que la relación profesional se desarrolla en un ambiente donde la tensión de poderes está de parte del profesional, quien asume un rol activo y experto, y promueve en los actores sociales roles más bien pasivos. Esta relación asimétrica en muchas ocasiones ubica al profesional en un territorio de comodidad. Esto es, en tanto el poder nos es asignado por "el otro/a", los trabajadores sociales parecemos solo responder frente al tipo de relación definido (Jarpa-Arriagada, Castillo y Toro, 2014).

Por otra parte, coincido con Duarte (2012), en el sentido de que las condicionantes del trabajo comunitario en Chile se constituyen en otro aspecto opaco del trabajo social emancipatorio. En efecto, tanto el sistema económico que genera pobreza y desigualdad como las políticas sociales basadas en el asistencialismo y la precariedad laboral, se levantan como fuertes limitantes a una perspectiva más crítica. Si sumamos a ello la primacía del cambio visto como reforma o la actividad reformista en general, podemos identificar la naturalización de procesos que contribuyen más a la perpetuación de las relaciones de opresión que a la emancipación de los sujetos. En suma, el dominio paradigmático del estructural-funcionalismo nos ha hecho pensar que, al reformar, estamos transformando, cuando todo indica que cuando reformamos solo estamos adaptándonos y adaptando a los sujetos/as a condiciones precarias de vida, a la conculcación de muchos o todos sus derechos, a la naturalización de relaciones de dominación y a la reproducción de estas, adquiriendo como trabajadores sociales un papel protagónico en dichos patrones de perpetuación.

Ergo, un trabajo social ético-político emancipatorio requiere de trabajadores sociales “activistas”, que cuestionen las estructuras de opresión, conscientes en su clase y de su clase; y produciendo concienciación. En efecto, la conciencia modificada es una precursora fundamental del cambio

\footnotetext{
${ }^{2}$ Villa Las Almendras es un territorio aledaño a la Universidad del Bío-Bío, sede La Castilla. Es un sector de 64 casas, fuertemente estigmatizado por el microtráfico de drogas. CIISETS trabaja con este territorio desde 2014 y actualmente existe praxis ligada a mujeres y niños, niñas y adolescentes.
} 
Prácticas de resistencia y trabajo social comunitario: forcejeos y tensiones ante las lógicas de dominación del modelo colonial y capitalista

estructural (Healy, 2001). Posiblemente, desde esta conciencia modificada se logre conseguir la lucha de despliegue múltiple en palabras de Gutiérrez-Aguilar (2017), y re-pensar la memoria y lo "popular" para volver indispensable el análisis de lo cotidiano y de las subalternidades, para resignificar lo político y lo ideológico en nuestras prácticas. Como afirma Duarte (2012), precisamente es en la dimensión pragmática donde los conflictos éticos se despliegan y donde tenemos que administrar nuestra adscripción institucional, nuestra vinculación con otras instituciones y nuestras proximidades con las personas, los grupos y las comunidades.

Para desafiar aquello nebuloso y sombrío de las intervenciones comunitarias actuales, planteo como un reto el desarrollo de la investigación activista. Esta modalidad ha sido conocida en nuestra profesión como investigación-acción participativa, pero viene renovada a partir de experiencias concretas en situaciones de fuerte compromiso social de los investigadores. En particular, Lipman (2017), desde la experiencia de trabajo con comunidades afroamericanas en Chicago, traduce este concepto como producción colaborativa del conocimiento, organización de la vida cotidiana como comunidad de lucha, aseguramiento de la no maleficencia y organización social centrada en la transformación. En tanto, para Fals-Borda (2015) una I-A-P asume la plena identificación del investigador con los investigados; su genuino interés supera la mera recogida de datos y asume un papel de colaborador activo de los propósitos de cambio de los sujetos que acompaña y estudia. El resultado es una disminución del papel de intelectualobservador, monopolizador y contralor de la información científica (Fals-Borda, 2015), para convertirse en un investigador activista, militante y político.

Hablamos de una inserción comunitaria donde las personas no son solo meros sujetos de investigación. El investigador se vuelve un activista de la causa emprendida por el grupo; lo acompaña, lo asesora y trabaja con ellos desde una lógica de compromiso social. Aquí no caben los utilitarismos y las comodidades. Las personas retoman su calidad de seres humanos con derechos, las comunidades retoman su conciencia e identidad propia. Los movimientos se nutren de sus saberes y los saberes populares nutren las intervenciones, por tanto, resulta imperioso conectarse con los sentidos barriales, populares, poblacionales.

Además, siguiendo a Netto (2008), debemos conocer nuestros límites profesionales, en el sentido de que ninguna acción profesional por sí misma, suprimirá la pobreza y la desigualdad del orden del capital. Conocer esos límites nos posibilita superar el mesianismo (creer que tenemos poderes redentores) y el fatalismo, como adhesión a-crítica a la burocracia elemental, omnisciente, omnipresente y omnipotente. En suma, adhiero a un trabajo social ético-político emancipatorio, que supera el colonialismo imperante. En palabras de Sousa Santos (2006), "responder al otro como sujeto de conocimiento es progresar en el sentido de elevar al otro del estatus de objeto al estatus de sujeto. Esta forma de conocimiento como reconocimiento es la que denomino solidaridad" (p. 26). 


\section{Consideraciones finales}

La politicidad del trabajo social debe rescatarse desde las fauces del capitalismo. Una vía para ese rescate son los trabajos sociales-otros. Si logramos poner en juego, pero además en tensión, nuestra matriz cognitiva con nuestra matriz operativa, podríamos experimentar una intensa relación dialéctica entre teoría y práctica. Ocuparnos sentipensantemente de las luchas y de los antagonismos de nuestras praxis, nutriría perfectamente una intervención comunitaria situada, con lectura histórica y recuperación de identidad y memoria, dónde emerja espontáneamente la red compleja de poder y donde superemos nuestras contradicciones en dirección a un trabajo social ético-político emancipatorio.

Afirmo que las universidades debemos avanzar hacia un mayor compromiso social con las comunidades aledañas a nuestros campus. En esta perspectiva proponemos un modelo de intervención comunitaria des-institucionalizado, que implica su materialización desde centros de estudio o formación, con acompañamiento directo de académicos/as universitarios/as.

Propongo la inmersión de grupos de estudiantes que, en ciclos, etapas o periodos, vayan desarrollando un despliegue múltiple en las comunidades y territorios, considerando cinco fases:

i. Inserción comunitaria consensuada con la comunidad;

ii. Rescate de la identidad comunitaria: mediante procesos de recuperación de memoria histórica;

iii. Consolidación de vínculos: renegociando permanentemente la necesidad de la praxis a la luz de una reflexión crítica sobre el asistencialismo;

iv. Investigación activista: con compromiso académico situado en los barrios;

v. Reflexión crítica permanente: que otorgue y verifique el sentido político de la práctica y de la formación.

Si un grupo de estudiantes, con asesoría académica directa, desarrolla procesos como este durante un periodo mínimo de tres años, estamos apostando a la co-construcción de un modelo de trabajo social ético-político emancipatorio. A lo menos, es nuestra experiencia en Villa Las Almendras, de la comuna de Chillán, Chile. Trabajar en comunidades y territorios desde una lógica situada nos permite lograr pertinencia en la intervención, pero también respeto por los sujetos; en palabras de Walsh (2007), "la especificidad del lugar como noción contextualizada y situada de la práctica humana” (p. 106), debe ser un componente ineludible en intervenciones críticas y congruentes con un trabajo social-otro.

Si los barrios participantes están inmersos en un territorio común se pueden potenciar nuevas conexiones, transmisión de experiencias, transferencia de buenas prácticas, reforzamiento del 
Prácticas de resistencia y trabajo social comunitario: forcejeos y tensiones ante las lógicas de dominación del modelo colonial y capitalista

tejido social. Podríamos estar actuando orgánicamente en código gramsciano y estaríamos construyendo sujetos con conciencia de clase. Desde los planteamientos de Fals-Borda (2015), investigar para transformar y combinar lo vivencial con lo racional es un imperativo para el cambio radical. Ergo, como se trata de un problema ontológico, para poder materializar este modelo "se requiere de educadores que, en su condición de intelectuales orgánicos, realicen un ejercicio de su práctica pedagógica orientada a generar las condiciones necesarias para la elevación de la conciencia social, ética y política de los educandos" (Jarpa-Arriagada, 2015, p. 133). En efecto, nos desafía a profundizar la formación ético-política de los nuevos/ as trabajadores/as sociales, pero también nos desafía a crear más proyectos fuera de la lógica funcional-estructural. Proyectos que encarnen el perfil de egreso declarado, donde la conexión con lo popular no sea sinónimo de lo que está al margen, sino de aquello que adquiere valor a la luz de las luchas diarias de actores sociales que afrontan día a día la desigualdad y la discriminación. Como afirma Scribano (2011): "Las marcas de los bordes constituyen los volúmenes relativos de vivencia del juego autonomía/heteronomía...” (p. 310). En nuestra postura de formación y praxis activista apostamos por la emancipación, esto es, por la autonomía.

\section{Referencias}

Arriagada, I. (2006). Formas y Complejidades de la Acción Afirmativa en la Educación Superior. En P. Díaz (Ed.), Acción Afirmativa: Vol. 5. Caminos para la Inclusión en la Educación Superior (pp. 93-100). Santiago de Chile, Chile: Fundación Equitas.

Canales, M. (2016). Trabajo Social y Reflexividad. En P. Vidal-Molina. (Ed), Trabajo Social en Chile. Un siglo de trayectoria (pp. 259-278). Santiago de Chile, Chile: RiL Editores.

De Sousa-Santos, B. (2006). Conocer desde el Sur: Para una cultura política emancipatoria. Lima, Perú: Fondo Editorial de la Facultad de Ciencias Sociales, UNMSM.

Drago, C., Moulian, T. y Vidal, P. (2011). Marx en el siglo XXI: La vigencia del (os) marxismo (s) para comprender y superar el capitalismo actual. Recuperado de http:/ /www.digitaliapublishing. $\mathrm{com} / \mathrm{a} / 13203$.

Duarte, C. (2012). Condicionantes de la intervención comunitaria en Chile. Revista Perspectivas, (23), 151-164.

Ezcurra, A. M. (2011). Igualdad en Educación Superior. Un desafío mundial. Los Polvorines, Argentina: Universidad Nacional de General Sarmiento; IEC-CONADU.

Fals-Borda, O. (2015). Una sociología sentipensante para América Latina. Buenos Aires, Argentina: Siglo XXI Editores y CLACSO. 
García-García, S. (2018). Trabajo social, colonialidad y fronteras. La intervención en la declinación de la cuestión social en cuestión cultural. Trabajo Social Global-Global Social Work, 8(14). doi: https://doi.org/10.30827/tsg-gsw.v8i14.6332.

Gaudichaud, F. (2015a). Las fisuras del neoliberalismo chileno:Trabajo, crisis de la “democracia tutelada” y conflictos de clases. Santiago de Chile, Chile:Tiempo robado editoras.

Gaudichaud, F. (2015b). Las fisuras del neoliberalismo maduro chileno: Trabajo, "democracia protegida” y conflictos de clases. Buenos Aires, Argentina: CLACSO.

Giraldo-Zuluaga, G. A. (2015). Ciudadanía: Aprendizaje de una forma de vida. Educación y Educadores, 18(1), 76-92. doi: https://doi.org/10.5294/edu.2015.18.1.5.

Gramsci, A. (1970). Antología. Madrid, España: Siglo XXI.

Gramsci, A. (1981). Cuadernos de la cárcel. Puebla, México: Universidad Autónoma de Puebla.

Gramsci, A. (1999). Introducción a la filosofía de la praxis. México, D.F., México: Fontamara.

Guerra, Y. (2007). El proyecto profesional crítico: estrategia de enfrentamiento de las condiciones contemporáneas de la práctica profesional. En M. Rozas y N. Ayalón. (Eds.), La profesionalización en trabajo social: rupturas y continuidades, de la reconceptualización a la construcción de proyectos ético-políticos (pp. 253-272). Buenos Aires, Argentina: Espacio Editorial.

Guerra,Y. (2018). Consolidar avanços, superar limites e enfrentar desafios: Os fundamentos de uma formação profissional crítica. Em E. de Carvalho (Ed), Serviço Social e seus fundamentos: Conhecimiento e crítica (pp. 25-46). Campinas, Brasil: Editora Papel Social.

Gutiérrez-Aguilar, R. (2017). Horizontes comunitario-populares: Producción de lo común más allá de las políticas estado-céntricas. Madrid, España:Traficantes de Sueños.

Healy, K. (2001). Trabajo social: Perspectivas contemporáneas. Madrid, España: Ediciones Morata; Fundación Paideia.

Jarpa-Arriagada, C. G. (2015). Función política de la educación en el pensamiento de Antonio Gramsci. Cinta de Moebio, (53), 124-134.

Jarpa-Arriagada, C. G., Castillo, P. y Toro, K. (2014). Significados que los sujetos de intervención le atribuyen a la relación profesional desarrollada con trabajadores sociales. Revista de Trabajo Social, Pontificia Universidad Católica de Chile, (87), 3-14.

Lipman, P. (2017). Responding to educational academic research and public engagement. Ponencia presentada en Congreso Interdisciplinario de Investigación en Educación, Santiago de Chile.

Maldonado-Torres, N. (2008). La descolonización y el giro des-colonial. Tabula Rasa, (9), 61-72. 
Prácticas de resistencia y trabajo social comunitario: forcejeos y tensiones ante las lógicas de dominación del modelo colonial y capitalista

Mejías, C. y Suárez, P. (2017). De aprendices a magos: configurando epistemologías y praxis, dos aspectos sustantivos en el resquebrajamiento epistémico-colonial neoliberal para el Trabajo Social. Revista Cuaderno de Trabajo Social, 1(10), 44-61.

Méndez, L. y Rojas, P. (2015). Principios orientadores en la intervención psicosocial y comunitaria centrada en infancia, interculturalidad y Buen Vivir. Polis, Revista Latinoamericana, 14(40), 123-142.

Mezzadra, S. (2013). Border as method, or, the multiplication of labor. Recuperado de http:// public.eblib.com/choice/publicfullrecord.aspx?p=1603738.

Mezzadra, S. y Neilson, B. (2017). La frontera como método: O la multiplicación del trabajo. Madrid, España: Traficantes de Sueños.

Molina, W. (2012). Implicancias éticas y políticas de la intervención social pos-dictadura en Chile. Revista Perspectivas, (23), 45-60.

Molina, W. (2016). Cuestión Social, transformaciones socioestructurales y trabajo social en el Chile post dictadura. En P. Vidal-Molina. (Ed), Trabajo Social en Chile. Un siglo de trayectoria (pp. 67-82). Santiago de Chile, Chile: RiL Editores.

Montaño, C. (2004). Hacia la construcción del Proyecto Ético-Político Profesional crítico. XVIII Seminario Latinoamericano de Escuelas de Trabajo Social-ALAETS. Seminario llevado a cabo en Costa Rica.

Montaño, C. (2007). Trabajo Social e intervención: la politización de la acción profesional. VII Coloquio Internacional de Estudiantes de Trabajo Social. Coloquio llevado a cabo en Perú.

Muñoz, G. (2018). Critical social work and the promotion of citizenship in Chile. International SocialWork, 61(6), 781-793. doi: https: // doi.org/10.1177/0020872816664965.

Netto, J. P. (2008). El orden social contemporáneo como desafío central. Revista de Trabajo Social, Pontificia Universidad Católica de Chile, (74), 31-46.

Quijano, A. (2007). Don Quijote y los molinos de viento en América Latina. Buenos Aires, Argentina: Editorial Biblos.

Sánchez, A. (2013). Prácticas de resistencia y alternativas para el cambio. Una defensa del Trabajo Social con colectivos y comunidades. Trabajo Social Global. Investigaciones en Intervención Social, 3(4), 157-176.

Scribano, A. (2011). Lo popular, lo subalterno y la decisión del Imperio. Recuperado de http: / / site. ebrary.com/id/10806661.

Suárez, P. (2018). El eterno retorno de la rebeldía o la búsqueda constante de los actos primordiales en la noción de Trabajos Sociales Otros. Congreso Vigencia del pensamiento crítico en el Trabajo Social: rupturas, continuidades y discontinuidades. Congreso llevado a cabo en Chillán, Chile. 
Suárez, P. (2019). Intervención social: Ensayo crítico descolonizador y radical. Buenos Aires, Argentina: Espacio Editorial.

Vidal-Molina, P. (Ed.). (2016). Trabajo social en Chile: Un siglo de trayectoria. Santiago de Chile, Chile: RiL Editores.

Vidal-Molina, P. (Ed.). (2017). Las caras del trabajo social en el mundo: Per(e)sistencias bajo el capitalismo tardío. Providencia, Chile: RiL Editores.

Vidal-Molina, P. (Ed.). (2019). Neoliberalismo, neodesarrollismo y socialismo bolivariano. Santiago de Chile, Chile: Ariadna Ediciones.

Vidal-Molina, P. y Vargas-Muñoz, R. (2019). Ciudadanía en tiempos del Capital. Una crítica desde la tradición marxiana. Convergencia Revista de Ciencias Sociales, (80), 1. doi: https: / / doi.org/10.29101/crcs.v26i80.10418.

Vivero-Arriagada, L. (2017a). Aportes del pensamiento latinoamericano al trabajo social crítico. Sophia Austral, (20), 71-81.

Vivero-Arriagada, L. (2017b). Trabajo Social entre el sentido común, hegemonía y praxis: Un análisis basado en Gramsci. Revista Latinoamericana de Ciencias Sociales, Niñez y Juventud, 15(1), 547-563. doi: https://doi.org/10.11600/1692715x.1513413052016.

Vivero-Arriagada, L. (2020a). Condiciones para una Neo-Reconceptualización del Trabajo Social en Chile, Latinoamérica y el Caribe. Prospectiva. Revista de Trabajo Social e Intervención Social, 29, 193-212. doi: https://doi.org/10.25100/prts.v0i29.824.

Vivero-Arriagada, L. (2020b). Reflexiones en torno al pensamiento de Gramsci y Freire: sus puntos de encuentro. Revista Eleuthera, 22(1), 192-210. doi: https://doi.org/10.17151/ eleu.2020.22.1.11.

Walsh, C. (Ed.). (2005). Pensamiento crítico y matriz (de) colonial. Quito, Ecuador: Universidad Andina Simón Bolívar: Abya-Yala.

Walsh, C. (2007). ¿Son posibles unas ciencias sociales/culturales otras?. Reflexiones en torno a las epistemologías decoloniales. Nómadas, (26), 102-113.

Walsh, C. (2013a). Lo pedagógico y lo decolonial. Entretejiendo caminos. En C. Walsh. (Ed), Pensamiento decolonial. Pedagogías decoloniales. Prácticas insurgentes de resistir, (re) existir y (re) vivir. Tomo I (pp. 23-68). Quito, Ecuador: Abya-Yala.

Walsh, C. (Ed.). (2013b). Pedagogías decoloniales: Prácticas insurgentes de resistir, (re)existir y (re) vivir. Quito, Ecuador: Abya Yala.

Zamanillo, T. y Martín, M. (2011). La responsabilidad política del Trabajo Social. Trabajo Social Global, 2(3), 97-115. 
Prácticas de resistencia y trabajo social comunitario: forcejeos y tensiones ante las lógicas de dominación del modelo colonial y capitalista

Zepke, N. (2015). What future for student engagement in neo-liberal times? Higher Education, 69(4), 693-704. doi: https://doi.org/10.1007/s10734-014-9797-y.

Zepke, N. (2018). Student engagement in neo-liberal times: What is missing? Higher Education Research \& Development, 37(2), 433-446. doi: https://doi.org/10.1080/07294360.2017 .1370440. 